\title{
The Effect of Aging on the Relaxation of Residual Stress in Cast Aluminum
}

\author{
LARRY A. GODLEWSKI, XUMING SU, TRESA M. POLLOCK, and JOHN E. ALLISON
}

\begin{abstract}
Most cast aluminum-engineered components are water quenched after the solution-treatment cycle of the casting process. This rapid water quenching has the potential to induce high residual stresses in regions of the castings. Reducing the amount of residual stress can have a promising effect on the life of the component. This study was conducted to quantify how aging affects the amount of residual stress in an aluminum casting. An engineered high residual stress test sample and quenching technique has been developed, and a relaxation study has been completed. The study focused on four different temperatures: $463 \mathrm{~K}, 493 \mathrm{~K}, 513 \mathrm{~K}$, and $533 \mathrm{~K}\left(190{ }^{\circ} \mathrm{C}, 220^{\circ} \mathrm{C}\right.$, $240{ }^{\circ} \mathrm{C}$, and $260{ }^{\circ} \mathrm{C}$ ) and a range of aging times ( 0.3 to 336 hours). The aging data were used to verify a stress relaxation model. The results indicated that as the aging temperature increased, the amount of relaxation of the residual stress increased.
\end{abstract}

DOI: $10.1007 / \mathrm{s} 11661-013-1800-1$

(C) The Minerals, Metals \& Materials Society and ASM International 2013

\section{INTRODUCTION}

THE use of aluminum in automotive applications has increased significantly over the last decade. Currently, aluminum castings are used in place of numerous traditional iron and steel components to reduce weight and improve fuel economy in automobiles. In addition, the casting process also allows for the consolidation of several components into single casting, thereby reducing cost and providing value addition to the automobile.

Part consolidations, demanding design requirements and high geometric tolerances, have resulted in very complex automotive castings like engine blocks and cylinder heads. To exceed the durability requirements for engine applications, the number of cast aluminum alloys that are being precipitation hardened has been steadily increasing. Precipitation hardening is a heat-treatment process which includes solution treatment, quenching, and an aging treatment. ${ }^{[1,2]}$

The thermal gradients induced by rapid water quenching or water spray can lead to a substantial amount of residual stress, which, in certain cases, can result in permanent, measurable part distortion and residual internal stresses. ${ }^{[3-7]}$ This situation is often the case in components such as engine blocks and cylinder

LARRY A. GODLEWSKI, Research Engineer, and XUMING SU, Technical Specialist, are with Ford Research and Innovation Center, Ford Motor Company, Dearborn, MI. Contact e-mail: lgodlews@ford.com TRESA M. POLLOCK, formerly Thesis Advisor with NAE, University of Michigan, Ann Arbor, MI, is now Professor of Materials, with NAE, UC, Santa Barbara, CA. JOHN E. ALLISON, Professor of Materials, Thesis Advisor, is with NAE, University of Michigan.

Manuscript submitted March 28, 2012.

Article published online May 23, 2013 heads that undergo water-quenching operation during the course of their heat-treatment process.

An example of this can be found in certain cast aluminum cylinder blocks that contain cast iron cylinder liners. Upon water quenching, residual stresses will arise because of two primary reasons. The first reason is attributed to dissimilar coefficients of thermal expansion between the aluminum and cast iron cylinder liner. Second, the residual stresses will arise because the complex structure of the block creates large thermal gradients within the block during quenching. If the residual stress is not properly relieved, then it can lead to distortion and/or cracking, resulting in reduced durability of the cast component. Therefore, a need exists to quantitatively understand how the heat-treatment process affects the residual stress at each step through the casting process, so that appropriate steps can be taken to minimize the amount of residual stress in a casting. ${ }^{[8-11]}$

\section{A. Residual Stresses}

Residual stresses are very difficult to predict in a casting; an inverse modeling approach is being developed at Ford Research Laboratory to predict the amount of residual stresses present in a casting. This approach is outlined in Figure 1, which describes the required tools that are used to predict residual stresses using an inverse modeling approach. A simulation package (Optcast*) is

*Optcast is a trademark of $\mathrm{ABC}$ Co.

used to develop heat-transfer coefficients based on experimental thermocouple data. The second step is to use the heat-transfer coefficients that were calculated from experimental data to predict thermal profiles for a specific casting geometry. Once the thermal profiles are accurately 
modeled in Procast software, a translator is used to convert the files from Procast** software to Abaqus

**Procast is a trademark of ESI Group.

software. Abaqus software will predict the resultant residual stress based on the quench data supplied from the Procast ${ }^{\dagger}$ software.

${ }^{\dagger}$ Abaqus is a trademark of Dassault Systems SA.

The stress analysis portion of the residual stress model uses a stress-strain relationship that evolves from theory and experimental testing. The following creep relation is assumed to determine the residual stress relaxation during aging. ${ }^{[12]}$

$$
\dot{\varepsilon}_{c}=A \sigma^{n} e^{-\frac{Q}{k T}}
$$

The $A, n$, and $Q$ are material parameters, which can vary with stress and temperature and are considered to be affected by precipitation in the alloy. The other parameters are $(\sigma)$ stress and temperature $(T)$, which will be the focus of the study. The creep strain $\left(\dot{\varepsilon}_{c}\right)$ or strain rate is affected by three variables: temperature, time, and internal residual stress.

Because all three variables can change the amount of stress in a casting, it is imperative that a study be conducted to determine how these factors influence the resultant residual stress and how the stress is reduced as a function of time and temperature. The complex design of typical component is much too difficult to use as a verification casting because there can be several confounding factors (local solidification conditions and geometry) that can influence the amount of residual

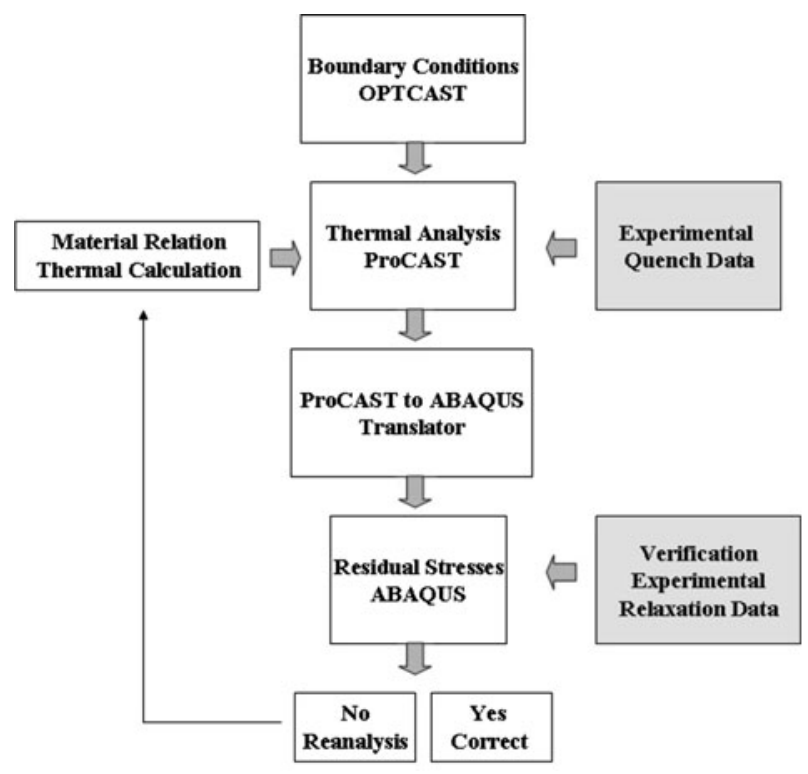

Fig. 1-Simulation process of the inverse modeling approach. stress in a casting. ${ }^{[13]}$ Therefore, it is imperative that a simple geometry be used to study how thermal effects influence the amount of residual stress in a casting.

\section{B. Residual Stress Measurement Techniques}

The standard techniques that researchers use to measure residual stresses in a material involve either the use of destructive or nondestructive testing conditions. Most destructive methods that attempt to measure residual stress actually measure changes in strain, which result from removing material by machining, and the stress is calculated using the elastic stress/strain tensor equations. Typically, a strain gage is used to measure the displacement caused by the release of residual stress. This technique has been used in various ways to characterize the amount of stress in a material. An example of the destructive technique is incremental hole drilling which attempts to characterize residual stresses at different regions corresponding to the hole. ${ }^{[14-17]}$

One of the nondestructive measurement methods of residual stress is by means of Rayleigh waves. This ultrasonic technique has been used to determine residual stresses present in thin sheet and plate materials. The technique is based on the method of relative variation of Rayleigh wave velocity $v s$ the depth in the sheets. ${ }^{[18,19]}$

The most common nondestructive technique is the neutron diffraction method. This method requires the use of a diffractometer where a monochromatic neutron beam interacts with a crystalline material, and the incident neutrons are subjected to diffraction at the planes of the atoms, producing strongly diffracted beams leaving in direction defined by Braggs law. ${ }^{[4,5,20-22]}$ This technique has the capability of examining large samples such as a cylinder block, but this technique is expensive and time-consuming.

\section{Residual Stress Experimental Casting}

Quantifying the amount of residual stress that exists within a complex geometry can be difficult. One approach to this problem is to create a similar residual stress phenomenon within a simple casting design. Some research has been done to try to re-create residual stress in cast aluminum using experimental ring geometry. [23] This technique is used to predict the amount of residual stress by measuring the amount of deflection in the ring during a rapid quenching and machining operation. The residual stress data were used to calibrate their stress model and attempt to use those data to predict strains in a production cylinder head.

\section{Residual Stress Relaxation in Cast Aluminum}

There is a lack of published information that documents the amount of residual stress relief after aging treatments in cast aluminum alloys. ${ }^{[4,24]}$ There is some speculation that during the aging cycle, the residual stress is relaxed after a certain time at temperature. It is understood that there are a number of features that can influence relaxation in aluminum and redistribution of residual stresses. Increasing the aging temperature 
lowers the yield stress and can introduce time-dependent (creep) deformation. ${ }^{[24]}$

Thus, the objective of this research is to develop a technique to further understand the amount of thermal stresses created by a steep thermal gradient and determine how these thermal stresses are relaxed as a function of time and temperature. Empirical calculations are often used for determining the amounts of stress and resultant strain associated with steep thermal gradients. The limitation to the empirical technique is that the stresses are unique for each alloy, heattreatment method, and casting geometry. An inverse modeling approach will be used to predict the amount of residual stress present in a test casting and validate the model in relation to experimental relaxation data.

Therefore, the objectives of the proposed research are as follows:

1. To quantify the amount of residual stress in aluminum using a simple casting design that produces a steep thermal gradient condition resulting in consistent residual stresses.

2. To develop time-temperature relaxation curves for E319 aluminum alloy with a 4-hour solution treatment @ $768 \mathrm{~K}\left(495^{\circ} \mathrm{C}\right)$ as a function of

- aging temperatures: $463 \mathrm{~K}, 493 \mathrm{~K}, 513 \mathrm{~K}$, and $533 \mathrm{~K}\left(190{ }^{\circ} \mathrm{C}, 220^{\circ} \mathrm{C}, 240{ }^{\circ} \mathrm{C}\right.$, and $\left.260{ }^{\circ} \mathrm{C}\right)$; and

- aging times (preferred times to enable proper verification of the condition).

3. Use the data from the experiment to validate an existing residual stress relaxation model.

\section{EXPERIMENTAL}

\section{A. Creation of Residual Stress Test Sample}

Because engine blocks are very large and expensive, an engineered test casting has been created to measure stress relaxation in cast aluminum. The test casting was inspired by the research done by Auburtin et al. who used a large oblong ring and a rapid quenching to replicate a substantial thermal gradient in a region of a test sample.

The test sample and quenching technique for this study were designed to produce a repeatable steep thermal gradient and have the ability to be strain gaged. To optimize the geometry of the specimen, a Finite Element (FE) Model was created in the commercial software package ABAQUS. The quenching process was modeled in several steps, as described later.

The quenching process is modeled in two parts. The thermal history is calculated using a diffusive heattransfer step (*HEAT TRANSFER). The stress history is then calculated in a separate static step (*STATIC) using the temperature history as a boundary condition. The geometry of the test sample is represented in the FE model by solid elements (DC3D8 and C3D8, respectively, for heat-transfer and stress steps). The geometry has symmetry about two planes; therefore, only $1 / 4$ of

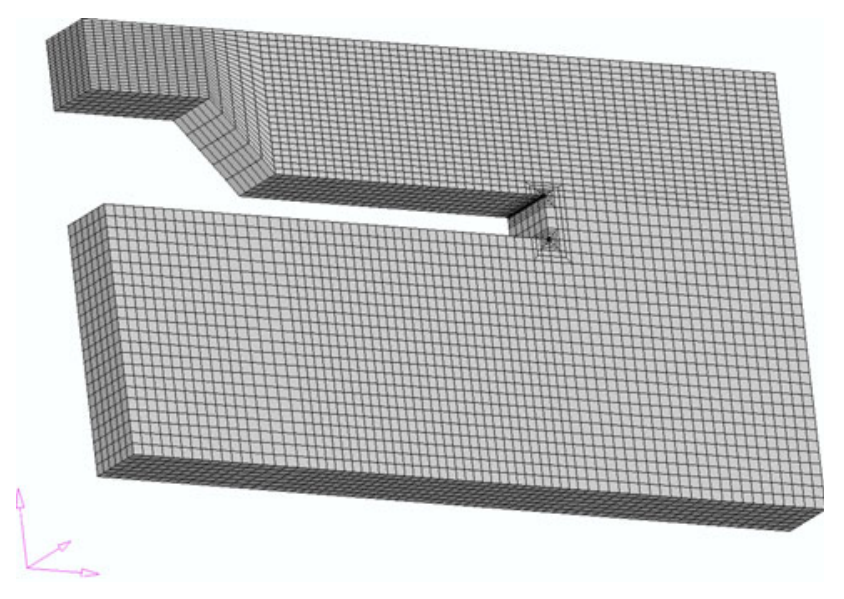

Fig. 2-Illustration of $1 / 4$ section of the mesh representing experimental casting used for quench simulation.

the geometry is represented in the FE model as shown in Figure 2.

The stresses are assumed to be uniformly zero throughout the sample following the machining process. The assumption of zero initial stress remains throughout the heating cycle, and the FE model is established at this equilibrium condition.

Heat transfer from the specimen is modeled as convective heat transfer (*SFILM) where the heattransfer coefficients were established by inverse modeling. Convection is assumed to occur on surfaces that are submerged during the experiment; all other surfaces are assumed to be insulated. An insulated boundary condition is assumed on the planes of symmetry. Conduction within the specimen is assumed to vary slightly with temperature, using a well-established curve for aluminum. The initial temperature of the material is $768 \mathrm{~K}$ $\left(495^{\circ} \mathrm{C}\right.$ ), and the convective medium (water) is assumed to be having a constant temperature of $294 \mathrm{~K}\left(21^{\circ} \mathrm{C}\right)$. The temperature step is of adequate duration to allow equilibrium to be established in the specimen at $294 \mathrm{~K}$ $\left(21^{\circ} \mathrm{C}\right)$.

The stress history is calculated using the temperature history as a prescribed boundary condition. Appropriate displacement boundary conditions are specified on the symmetry planes, and further constraints are applied to remove rigid body motion. The constitutive model is proprietary, where the results described in this study are used to establish the model. The stress history is calculated for the same time duration as is used to establish equilibrium in the thermal history. At the end of this time step, the elastic strains are compared with the elastic residual strains measured on the test specimen.

Subsequent to the calculation of the residual stresses, two additional steps are included in the ABAQUS model to model stress relaxation. At all nodes, the temperature is uniformly raised to the heat-treatment temperature in a static step (*STATIC). Finally, a viscoplastic step is included (*VISCO), where the material constitution is calibrated against the results described in the current study. Elastic strains are tracked throughout 
the time history during this step, for comparison with experimental data.

The engineered experimental test casting is illustrated in Figure 3 and will be referred to as Residual Stress Test Casting RSTC in the remainder of the current article.

The sample is placed into an oven and heated slowly (maintaining uniform temperature) to the solutiontreatment temperature. Before the samples were subjected to the quench bath, a $1-\mathrm{mm}$ thin sheet of aluminum is inserted into the slot in the test sample. This thin sheet is significant to insure that the critical region of the sample remains isolated and free from any water during the quenching process. A schematic of the experimental quench setup is illustrated in Figure 4.

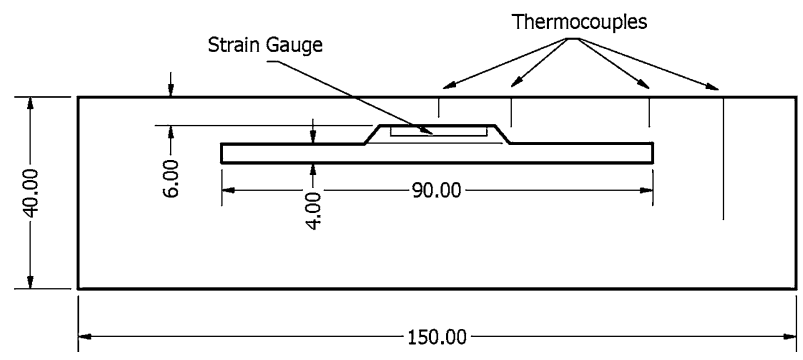

Fig. 3-Engineering drawing of the residual stress test casting sample geometry. Thermocouple IDs from left to right: bridge region, center \#1, center \#2, and outside. Dimensions are given in millimeters.

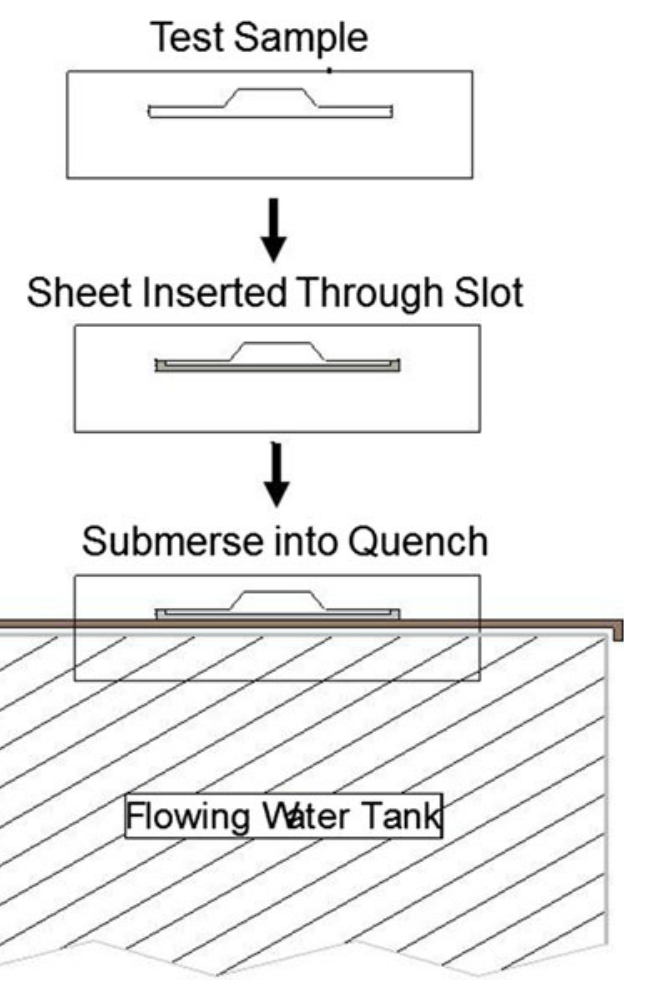

Fig. 4-Schematic of quench setup for residual stress relaxation samples.

\section{B. Experimental Details}

The material that will be used for this study is a variation of the commercially available Aluminum Association 319-type alloy; this alloy has different composition ranges for $\mathrm{Si}, \mathrm{Fe}, \mathrm{Mg}$, and $\mathrm{Mn}$ and will be referred to as $E 319$ aluminum in the remainder of the current article. The nominal composition range for E319 is given in Table I.

The E319 aluminum alloy was melted in an electric resistance furnace. The alloy was melted and degassed using a rotary flux-degassing unit (nitrogen purge with a salt-based flux) for 10 minutes. After degassing, a target of 0.015 pct $\mathrm{Sr}$ was added to the melt in the form of Al10 pet $\mathrm{Sr}$ master alloy; the $\mathrm{Sr}$ was then allowed to homogenize in the melt for at least 30 minutes before casting. The target casting temperature was $1003 \mathrm{~K}$ $\left(730^{\circ} \mathrm{C}\right)$, and the total metal poured into the casting was approximately $1100 \mathrm{~g}$. The approximate filling time for the casting was 4 seconds. An AlScan Hydrogen Analyzer was used to monitor the amount of $\mathrm{H}_{2}$ gas flowing into the melt, and the measurement of flow rate was $0.160 \mathrm{~mL} / 100 \mathrm{~g}$. Chemical analysis samples were taken at several points in the pouring process. A compositional analysis was performed on several samples, and the limit of accuracy of the compositional analysis is \pm 5 pct of the measured value.

Test plate castings were used to provide material for the RSTC samples. The "plate" castings were designed to provide large numbers of test specimens with uniform microstructures for mechanical property testing. The plates were cast using a rollover casting technique and allowed to solidify. A 3 "-thick copper chill was located at one end of the plate casting to induce a large thermal gradient throughout the plate casting. The overall dimensions for the plate are $150 \mathrm{~mm} \times 150 \mathrm{~mm} \times 20 \mathrm{~mm}$. The portion of the plate that is closest to the copper chill had been removed for another study. Rectangular bars were taken from the adjacent section and used for the current study. Each of the bars was identified at one end to indicate the faster solidification time section of the bar. The bars were machined into the final dimensions (Figure 3), and the slot was cut using an EDM process.

Metallographic samples were prepared for an optical examination. Samples were mounted in Bakelite and were rough ground and finally polished. Digital micrographs were taken, and $>125$ individual dendrites were measured from the samples at the bridge region of the RSTC to verify the microstructure and solidification condition.

Table I. Composition of the E319 Aluminum Alloy

\begin{tabular}{lc}
\hline Element & E319 $($ Weight Percent) \\
\hline $\mathrm{Si}$ & 6.5 to 8.5 \\
$\mathrm{Cu}$ & 2.0 to 4.0 \\
$\mathrm{Fe}$ & 0.7 max. \\
$\mathrm{Mn}$ & $0.6 \max$. \\
$\mathrm{Mg}$ & 0.05 to 0.5 \\
$\mathrm{Ti}$ & 0.25 max. \\
$\mathrm{Sr}$ & $0.05 \max$. \\
Others & 0.50 max. \\
\hline
\end{tabular}




\section{Relaxation Technique}

All of the RSTC samples were subjected to a 4-hour solution treatment at $768 \mathrm{~K}\left(495^{\circ} \mathrm{C}\right)$ followed by an immediate quenching of the bottom half of the sample to reach $283 \mathrm{~K}\left(10^{\circ} \mathrm{C}\right)$ water, to induce the high residual stress condition. After the quenching process was complete, six baseline samples were subjected to an artificial aging treatment at any one of the following temperatures: $463 \mathrm{~K}, 493 \mathrm{~K}, 513 \mathrm{~K}$, or $533 \mathrm{~K}\left(190{ }^{\circ} \mathrm{C}, 220{ }^{\circ} \mathrm{C}, 240{ }^{\circ} \mathrm{C}\right.$, or $260^{\circ} \mathrm{C}$ ) followed by an air quenching. The duration at temperature will vary between 0.2 and 350 hours depending on the test matrix in Table II. Aging treatments for $<1.0$ hour were performed in a PARTHERM ${ }^{*}$ salt

${ }^{\ddagger}$ PARTHERM is the trademark of Heatbath Corp. Park Metallurgical, Indian Orchard, MA.

bath followed by air quenching.

The relaxation samples were aged in an electricalresistance box furnace for preferred time durations and set to cool on a refractory brick. Upon cooling, uniaxial style strain gages were used to measure the unknown principal strains in the test casting. The gages used were uniaxial strain gages from Measurements Group Inc., Raleigh, NC. The type of gage was CEA-13-250UW-120. The gages are placed on the inner surface of the as shown in Figure 5. This location was chosen because of the temperature gradient imposed by the quenching process. After the gages are attached to the RSTC samples, the bridges are sectioned using a band saw. The strain is

Table II. Experimental Matrix

\begin{tabular}{lllll}
\hline Aging & & & & \\
Temperature & 463 & 493 & 513 & 533 \\
{$\left[\mathrm{~K}\left({ }^{\circ} \mathrm{C}\right)\right]$} & $(190)$ & $(220)$ & $(240)$ & $(260)$ \\
Aging & 1.0 & 0.5 & 0.2 & 0.3 \\
Times (h) & 66 & 2.0 & 1.0 & 1.0 \\
& 336 & 8.0 & 3.0 & 5.0 \\
& 1500 & 18 & 18 & 21 \\
& & 113 & 91 & 114 \\
\hline
\end{tabular}

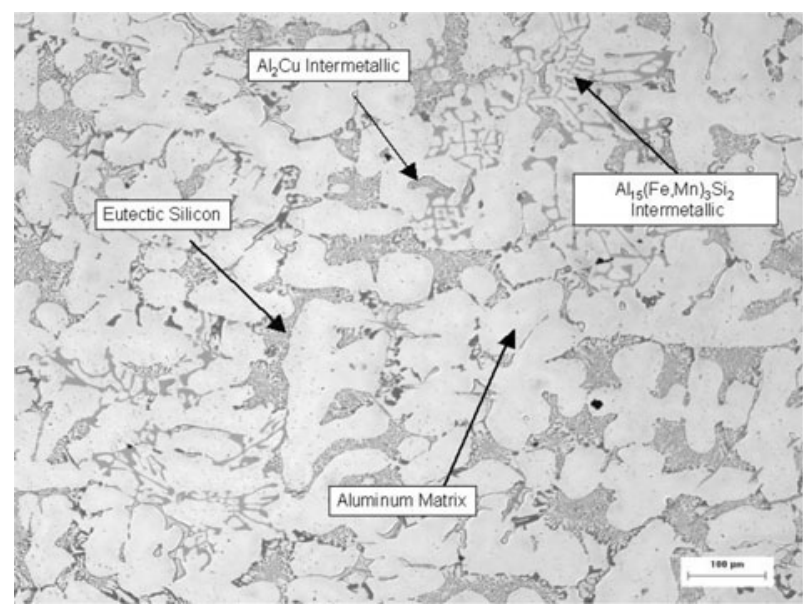

Fig. 5-Typical microstructure observed in the bridge region of the castings. recorded using a software/hardware package called Strain Smart. The data are collected at a sample rate of $0.1 \mathrm{~Hz}$ during the sectioning and the recording continued for $\sim 1.0$ minute after the sample has been sectioned.

Thermocouples were installed (to develop technique) in the casting to understand the various cooling rates throughout the top of the sample as shown in Figure 3. The thermocouples used for this study were type "K" stainless steel-sheathed thermocouples with a diameter of $0.020^{\prime \prime}$, and the data were collected at a sample rate of $0.01 \mathrm{~Hz}$.

\section{RESULTS}

\section{A. General Microstructure}

The chemical analysis results from the test castings are presented in Table III. This composition falls within the ranges given in Table I.

Figure 5 is a representation of the microstructure for the material that is located in the bridge region of the RSTC. The microstructure consists of primary dendrites surrounded by finely dispersed $\mathrm{Si}$ particles resulting from the high $\mathrm{Sr}$ concentration. There are also $\mathrm{Al}_{15}(\mathrm{Fe}, \mathrm{Mn})_{3} \mathrm{Si}_{2}-\mathrm{Fe}$ script particles present in the aluminum dendrites. These script particles are common in a material with $>0.4$ wt pet $\mathrm{Fe}$ concentration. The secondary dendrite arm spacing in the bridge region of the casting is $31.3 \pm 7 \mu \mathrm{m}$. This dendrite arm spacing is equivalent to $\sim 42$ seconds of solidification time.

\section{B. Baseline Quench-Cooling Curves}

In order to characterize the thermal history of the RSTC during the quenching process, several repetitions of the quench were performed to record the results from the four locations of the thermocouples as illustrated in Figure 6. Quenching rates were calculated between $573 \mathrm{~K}$ and $673 \mathrm{~K}\left(300{ }^{\circ} \mathrm{C}\right.$ and $\left.400{ }^{\circ} \mathrm{C}\right)$ for each of the locations and summarized in Table IV. Comparison of the different quenching rates indicates a nearly significant difference between the bridge region and the outside region of the sample.

\section{Statistical Analysis for Baseline Sample}

In order to determine if 6 as the number of samples is an accurate representative of the total population of the baseline condition, a statistical analysis was performed. A sample size and power from a full factorial design was

Table III. Composition of the E319

\begin{tabular}{lc}
\hline Element & E319 \\
\hline $\mathrm{Si}$ & 7.53 \\
$\mathrm{Cu}$ & 3.39 \\
$\mathrm{Fe}$ & 0.69 \\
$\mathrm{Mn}$ & 0.32 \\
$\mathrm{Mg}$ & 0.23 \\
$\mathrm{Ti}$ & 0.11 \\
$\mathrm{Sr}$ & 0.023 \\
Others & 0.50 max. \\
\hline
\end{tabular}




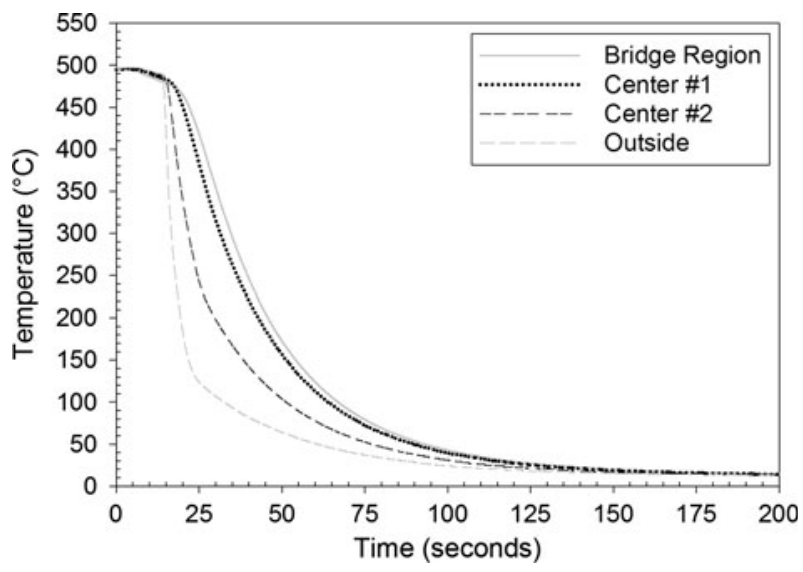

Fig. 6-Temperature history of quenched RSTC samples measured at four locations.

Table IV. Quenching Rates for the Baseline Quench Condition

\begin{tabular}{lclll}
\hline Location & $\begin{array}{c}\text { Outside } \\
\text { (Submersed) }\end{array}$ & Center 2 & Center 1 & $\begin{array}{c}\text { Bridge } \\
\text { Region }\end{array}$ \\
\hline $\begin{array}{l}\text { Quenching } \\
\text { Rate K/s }\end{array}$ & $350(77)$ & $300(27)$ & $286(13)$ & $385(12)$ \\
{$\left[\mathrm{T}\left({ }^{\circ} \mathrm{C}\right)\right]$} & & & & \\
\hline
\end{tabular}

calculated using a one-way ANOVA. ${ }^{[25]}$ The following assumptions were used in the analysis:

- Sigma value $=146 \mu \varepsilon$ (calculated 50 baseline samples)

- Alpha value $=0.05$

- Target power level $=0.9$

The statistical results from the one-way ANOVA indicated that to distinguish a difference of $400 \mu \varepsilon$ between the populations. Six samples can be used to achieve this difference with a power level of 0.94 . Therefore, if the total difference in relaxation is less than the $400 \mu \varepsilon$, then it is likely that more samples are required to be used.

\section{Baseline Data as a Function of Quenching Temperature from Experimental Results}

Figure 7 summarizes all the baseline data of samples that were quenched over a specific range of temperatures. This range of temperatures came to exist because cold tap water was the source for the quenching media, and the fluctuation in temperature was due to the ground water temperature. The figure indicates that the stress concentration in the critical bridge region of the sample does not appear to be sensitive to the range of water-quenching temperatures used during the experiment. As shown, the range of water temperatures used in this study varied by $\sim 273 \mathrm{~K}\left(10{ }^{\circ} \mathrm{C}\right)$ with no apparent increase or decrease in the measured strain. Additional samples were tested at $373 \mathrm{~K}\left(100{ }^{\circ} \mathrm{C}\right)$ to determine if there was a substantial change in strain. The measured

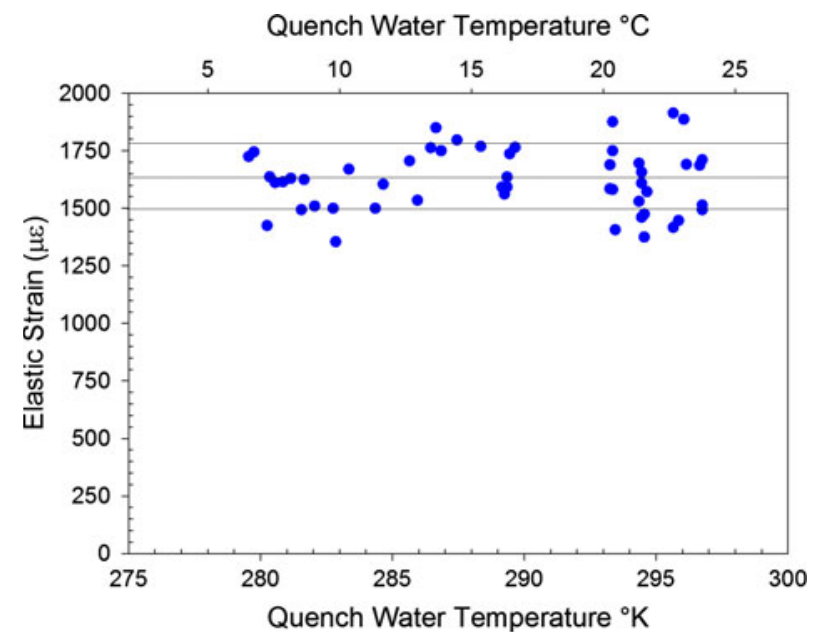

Fig. 7-Results from measured strain data for samples tested in the baseline condition.

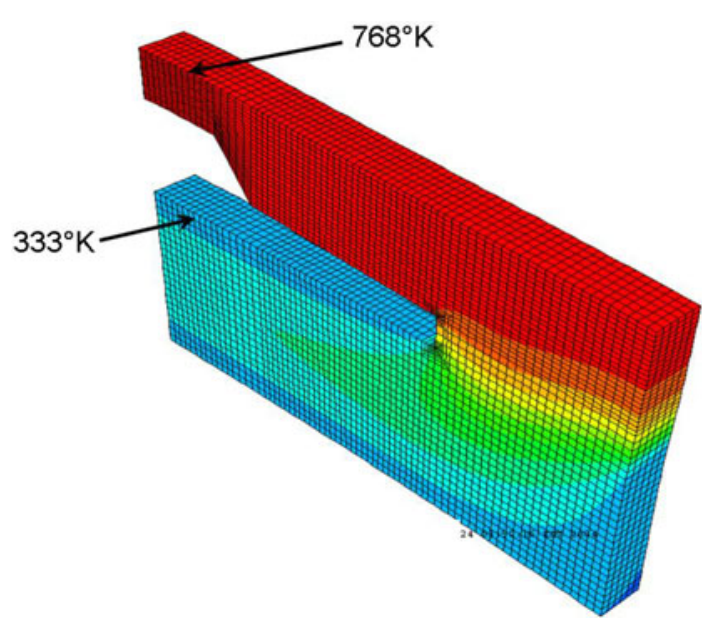

Fig. 8 - Simulation of thermal gradient during $294 \mathrm{~K}\left(21^{\circ} \mathrm{C}\right)$ water quenching.

strain at $293 \mathrm{~K}\left(20^{\circ} \mathrm{C}\right)$ is $\sim 10$ times higher than that measured from the samples quenched in boiling water.

The average and standard deviation were calculated from all of the baseline samples and will be used as the initial reference value for the relaxation study. The average was $1632 \mu \varepsilon$, and the standard deviation was $144 \mu \varepsilon$.

\section{E. Baseline Data from Model Predications}

The results from the simulation in Figure 8 indicate that there is a significant temperature gradient throughout the sample. The bridge section is $768 \mathrm{~K}\left(495^{\circ} \mathrm{C}\right)$, and the section in the water had been quenched to $<373 \mathrm{~K}\left(100^{\circ} \mathrm{C}\right)$. In addition, there is a significant gradient in stress throughout the thickness of the bridge. There is however a 1-mm-thick region on the bottom of the bridge region that is uniform in stress and was used for the relaxation study — shown highlighted in Figure 9. 
The calculations were done using a commercial FE code in ABAQUS. A 3D mesh was created to with 1$\mathrm{mm}$ function elements. Only a quarter of the mesh was simulated from the residual stress test casting because of symmetry about the cut planes. The elastic modulus was taken as $71 \mathrm{Gpa}$, and the Poisons ratio was set to 0.33 . Different boundary conditions were used for the bottom of the sample because this portion of the sample was submersed under the water during the quench.

\section{F. Relaxation Data for $533 \mathrm{~K}\left(260^{\circ} \mathrm{C}\right)$}

The experimental results for the $533 \mathrm{~K}\left(260{ }^{\circ} \mathrm{C}\right)$ aging section are illustrated in Figure 10. The data indicate that for the first 5 hours of relaxation there is a rapid decrease in measured strain. It appears that after this amount of time that it is also sufficient enough to achieve $\sim 50$ pct decrease in total measured strain. Further time at temperature will continually relax the material but at a much slower rate, resulting in a final strain of $387 \mu \varepsilon$ after 114 hours.

\section{G. Relaxation Data for $513 \mathrm{~K}\left(240^{\circ} \mathrm{C}\right)$}

The results for the $513 \mathrm{~K}\left(240{ }^{\circ} \mathrm{C}\right)$ aging are similar for the aging temperature of $533 \mathrm{~K}\left(260{ }^{\circ} \mathrm{C}\right)$, but the

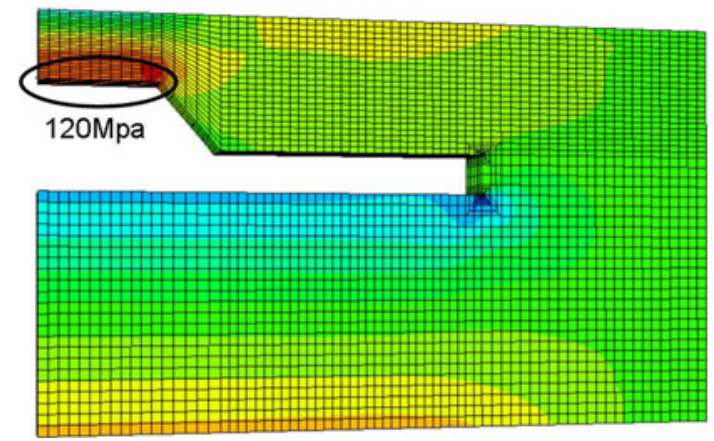

Fig. 9-Simulation of thermal stress during $294 \mathrm{~K}\left(21^{\circ} \mathrm{C}\right)$ water quenching.

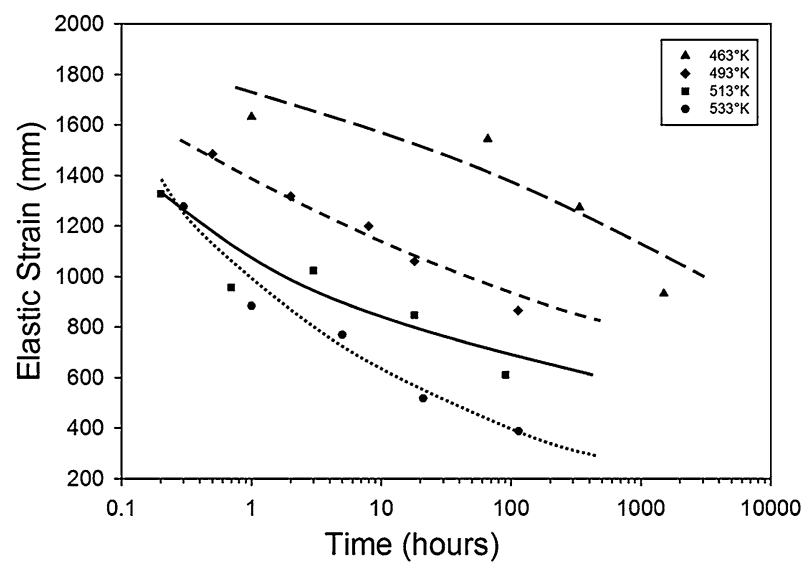

Fig. 10 - Comparison of experimental relaxation data points for aging temperatures of $533 \mathrm{~K}, 513 \mathrm{~K}, 493 \mathrm{~K}$, and $463 \mathrm{~K}\left(260{ }^{\circ} \mathrm{C}\right.$, $240{ }^{\circ} \mathrm{C}, 220^{\circ} \mathrm{C}$, and $190{ }^{\circ} \mathrm{C}$ ). (Reference lines are drawn and do not represent model). total relaxation is not as severe as shown in Figure 10. The relaxation continues to decrease until about 18 hours in which additional time at temperature only provides an additional 15 pct decrease.

In order to achieve a 50 pct reduction in strain, the sample must be subjected to $513 \mathrm{~K}\left(240{ }^{\circ} \mathrm{C}\right)$ for $\sim 18.0$ hours. In comparison, the $533 \mathrm{~K}\left(260{ }^{\circ} \mathrm{C}\right)$ samples only takes 5 hours to achieve a 50 pct reduction.

\section{H. Relaxation Data for $493 \mathrm{~K}\left(220^{\circ} \mathrm{C}\right)$}

The results of the $493 \mathrm{~K}\left(220{ }^{\circ} \mathrm{C}\right)$ aging treatment are summarized in Figure 10. The results indicate that after 8 hours at temperature, there is only a 25 pct reduction in measured strain. It is not possible to reach a $50 \mathrm{pct}$ reduction in strain with $493 \mathrm{~K}\left(220^{\circ} \mathrm{C}\right)$ unless aging time is longer than ( $>113$ hours).

\section{Relaxation Data for $463 \mathrm{~K}\left(190^{\circ} \mathrm{C}\right)$}

The summarized relaxation data indicate that the amount of relaxation that was measured during the $463 \mathrm{~K}\left(190^{\circ} \mathrm{C}\right)$ aging portion was $<350 \mu \varepsilon$. After 1 hour at temperature there was no measurable relaxation in the sample. If the sample is subjected to an additional 65 hours at temperature there is only a 5 pct decrease in the measured strain.

\section{J. Application of Power Law Creep Equation to Experimental Data}

In order to determine the material constants from the relaxation curves that were developed from the experimental data, calculations were performed to solve for each of these unknown values using the following relations:

$$
\begin{aligned}
\varepsilon_{\mathrm{total}} & =\varepsilon_{\mathrm{el}}+\varepsilon_{\mathrm{cr}} \\
\varepsilon_{\mathrm{cr}} & =\mathrm{A} \sigma^{n} e^{-Q / R T}
\end{aligned}
$$

The $\ln \left(\varepsilon_{\mathrm{cr}}\right) v s \ln (\sigma)$ was plotted to determine the slope for each set of temperatures. The results from the slopes are shown in Table V. Because the variability of the calculated $\mathrm{n}$ for each aging temperature was not clearly understood, the average value was used for the remaining portion of the analysis.

Determining $\mathrm{Q}$ can be accomplished by taking the $\ln \left(\varepsilon_{\mathrm{cr}} / \sigma^{n}\right)$ and plotting it $v s 1 / T$. The slope from this plot for each of the temperatures will indicate the $-Q / R$ slope and the intercept will be the $\ln (A)$. The calculated

Table V. Calculated $n$ Values from Experimental Data for All Four Temperatures

\begin{tabular}{lc}
\hline Temperature $\left[\mathrm{K}\left({ }^{\circ} \mathrm{C}\right)\right]$ & Calculated $n$ \\
\hline $463(190)$ & 4.3 \\
$493(220)$ & 10.2 \\
$513(240)$ & 8.8 \\
$533(260)$ & 5.7 \\
Average & 7.24 \\
\hline
\end{tabular}


$n=7.24$ and $Q=513 \mathrm{~kJ} / \mathrm{mol}$ which are comparable to values found in literature. ${ }^{[30-33]}$

The calculated constants from above were used in Eq. [1] to determine the strain rates for each of the test temperatures. These results were plotted against the measured strain rates from the experimental results and are shown in Figure 11. The plot indicates that there are some differences between the calculated strain rates and those interpreted from the experimental data.

In addition, a second technique was used to determine the activation energy for the experimental data shown in Figure 12. Relaxation data were taken at 10, 25 and 50 pct time to relaxation. The data were plotted against temperature. The results for this technique were similar to that calculated using the method described above.

\section{K. Calculated Constants used in FEA Model Predictions}

The calculated constants were used in the FEA model to determine if the constants would accurately predict

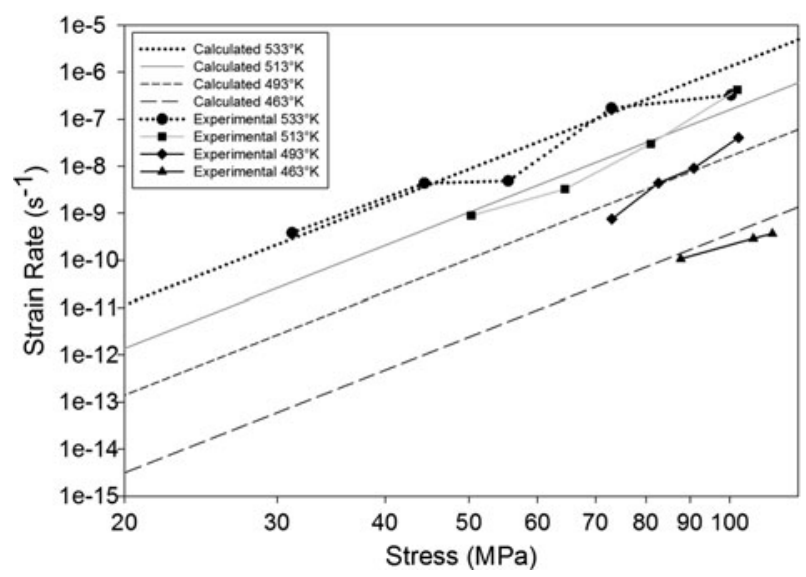

Fig. 11-Strain rates from calculated constants using the Power Law equation and experimental results.

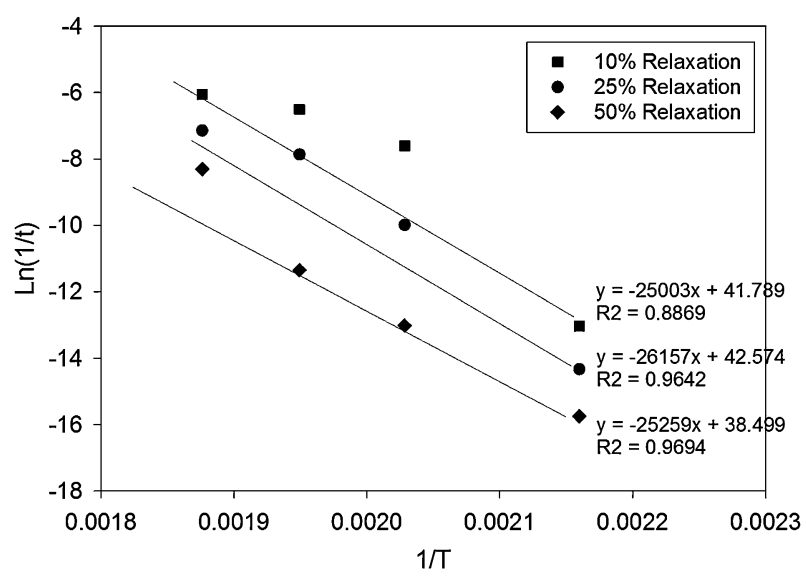

Fig. 12-Strain rates from 10, 25 and 50 pct and plotted against the temperature. relaxation. Figures 13(a) and (b) summarize the experimental data plotted along with the values determined by a FEA model using the calculated constants described in the previous section. Using the calculated values of $\mathrm{n}$ and $\mathrm{Q}$ reduced the difference between the predictions and the experimental data to less than 10 pet.

\section{Aging Response}

The aging response was characterized for each of the relaxation conditions by taking hardness measurements. Rockwell $E$ hardness measurements were taken (two samples) from each of the relaxation conditions to verify the amount of $\theta^{\prime}$ coarsening that was occurring during the aging treatment. As shown in Figure 14, at each stage during the relaxation study, there is a continuous decrease in hardness as a function of time. These results are on the expected lines and correspond very well with prior study. ${ }^{[26,27]}$

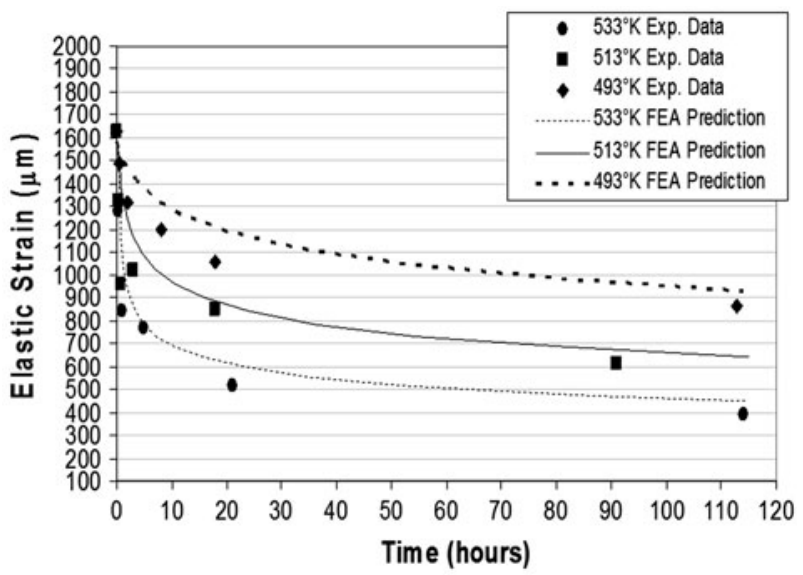

(a)

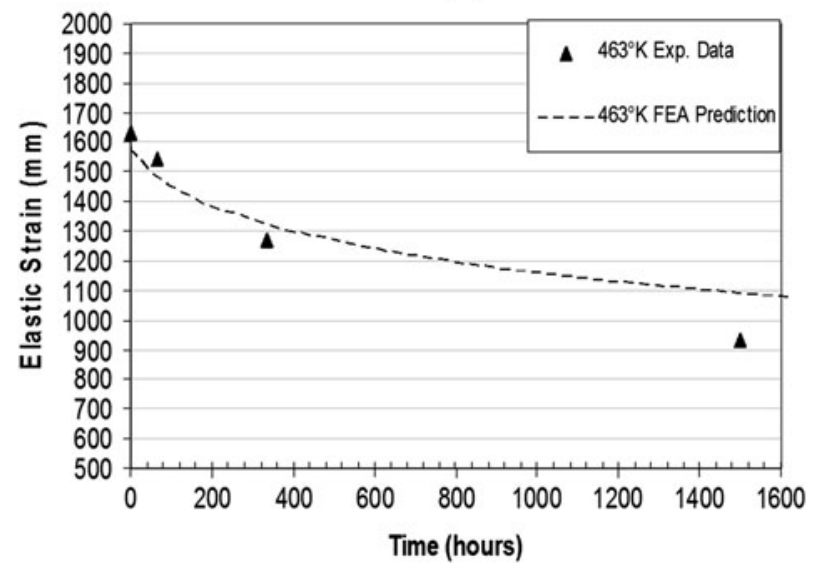

(b)

Fig. 13 - (a) FEA predictions and experimental results determined using calculated constants from Power Law equation. (b) FEA and experimental results determined using calculated constants from Power Law equation. 


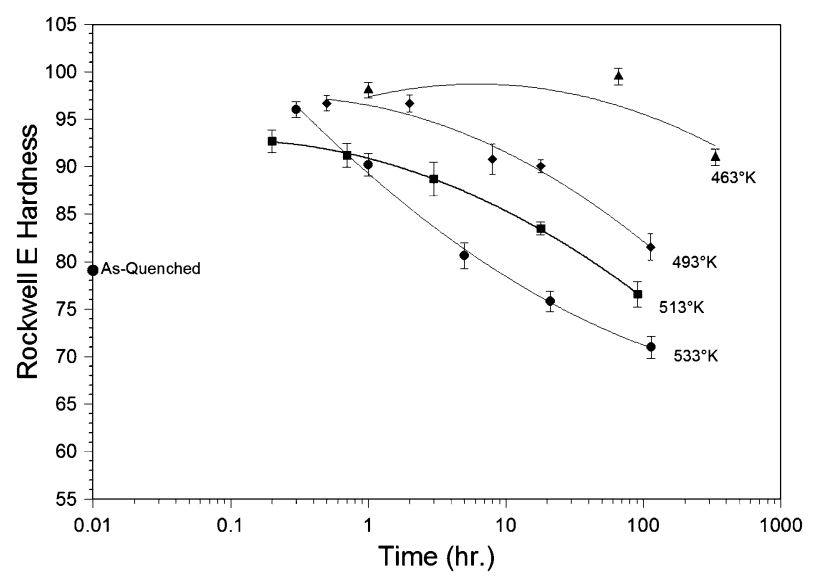

Fig. 14-Age-hardening curves for each of the relaxation temperatures.

\section{DISCUSSION}

A. The Effect of Aging on Relaxation of Residual Stress in E319 Aluminum Alloy as a Function of Temperature

The main focus of this study was to understand the effect of aging on residual stress in aluminum alloy. The results presented in Figure 10 show that for aging temperature of $533 \mathrm{~K}\left(260{ }^{\circ} \mathrm{C}\right)$, time has a strong effect on the relaxation of residual stress in E319 aluminum alloy. In general, as the aging time increased, significant decreases were observed in the reduction of residual stress. The initial stress in the residual stress test casting was equivalent to $112 \mathrm{Mpa}$, and after 114 hours at $533 \mathrm{~K}\left(260{ }^{\circ} \mathrm{C}\right)$, it was reduced to $26 \mathrm{Mpa}$. Also, after 1 hour, there was a 50 pct decrease in the initial stress resulting in a final stress of $57 \mathrm{Mpa}$.

Similar effects were also observed for the aging temperatures of $513 \mathrm{~K}\left(240{ }^{\circ} \mathrm{C}\right)$ as shown in Figure 10; however, the rate at which relaxation occurs is much slower than the higher temperature. The initial stress was also $112 \mathrm{Mpa}$, which was reduced to $42 \mathrm{Mpa}$ after 91 hours at $513 \mathrm{~K}\left(240{ }^{\circ} \mathrm{C}\right)$. It is highly probable that if longer durations were chosen in the experimental matrix, then the final stress would be reduced to a nominal value.

The results for the aging temperature of $493 \mathrm{~K}\left(220^{\circ} \mathrm{C}\right)$ as shown in Figure 10 indicate that there is an effect of aging time; however, the rate at which the relaxation has been induced is drastically reduced. The final stress after 113 hours at $493 \mathrm{~K}\left(220^{\circ} \mathrm{C}\right)$ was $59 \mathrm{Mpa}$, which is similar to the stress recorded after 1 hour at $533 \mathrm{~K}$ $\left(260{ }^{\circ} \mathrm{C}\right)$. This drastic difference in the amount of relaxation demonstrates that the higher temperatures are required if short aging times are to be used in production.

Aging at $463 \mathrm{~K}\left(190{ }^{\circ} \mathrm{C}\right)$ is not beneficial in the reduction of residual stress for short aging times. After aging for 336 hours, there is still a residual stress of $88 \mathrm{Mpa}$ remaining in the sample.

\section{B. Creep Mechanism Initiating the Relaxation of Residual Stress in E319 Aluminum Alloy}

Normalized tensile stress calculations were performed for each of the aging conditions to determine which creep mechanism was the most dominant to be inducing the relaxation. After the calculations were completed and plotted, it is apparent that for each of the durations and temperatures measured in this study, the only possible mechanism responsible for the relaxation is that of dislocation creep.

In addition, the primary creep mechanism was also verified by calculating strain rates for all of the creep mechanisms (Cobble, NH, and Power Law). The results of this experiment indicate that the Power Law yielded the largest strain rate, which can be interpreted as the strain rate that is associated with the dominant creep mechanism.

\section{The Effect of Aging on Hardness of E319 Aluminum Alloy as a Function of Temperature}

It has been observed that the structure and morphology of the precipitates are controlled by elevated aging times and temperatures. Prior study has been done to characterize the precipitation sequence of this alloy as a function of time and temperature. ${ }^{[28]}$ The aging temperatures used in study are similar, and the results from the hardness tests indicate that all four conditions have transitioned past peak hardness. This indicates that at this point of the precipitation sequence, the $\theta^{\prime}$ phase has coarsened and the equilibrium $\theta\left(\mathrm{Al}_{2} \mathrm{Cu}\right)$ precipitate is occurring. Tetragonal in shape, the $\theta$ phase is completely incoherent with the matrix, relatively large in size, and has a coarse distribution within the aluminum matrix. Macroscopically, this change is typically observed to result in a decrease in hardness and tensile strengths of this alloy. ${ }^{[29]}$ The authors of the current study at this point cannot determine the influence of these precipitates and how they affect the relaxation that was occurring in the study.

\section{The Effect of Aging on Relaxation of Residual Stress in E319 Aluminum Alloy as a Function of Temperature}

The experimental results indicate if aging temperature of $533 \mathrm{~K}\left(260{ }^{\circ} \mathrm{C}\right)$ is used, after 1-hour duration at this temperature, there was a 50 pct decrease in the initial measured strain. Additional 4 hours did not yield a substantial benefit. It is highly probable that if longer times were chosen in the experimental matrix, the final strain would have been reduced to a nominal level. Similar change was also observed for the aging temperature of $513 \mathrm{~K}\left(240{ }^{\circ} \mathrm{C}\right)$; however, at a slower rate as compared to the higher temperature. After 18 hours, a 50 pct decrease in the initial measured strain was achieved. Artificial aging at $493 \mathrm{~K}\left(220^{\circ} \mathrm{C}\right)$ temperature was not able to reduce the strain by 50 pct during the aging times tested in the current study.

Aging at $463 \mathrm{~K}\left(190{ }^{\circ} \mathrm{C}\right)$ did not appear to be beneficial in reducing the residual stress. Artificial aging for 1500 hours only resulted in a 40 pet reduction in residual stress in the thin bridge region of the sample. It is quite apparent that as the artificial aging temperature is decreased from $533 \mathrm{~K}$ to $463 \mathrm{~K}\left(260{ }^{\circ} \mathrm{C}\right.$ to $\left.190{ }^{\circ} \mathrm{C}\right)$, the total amount of relaxation is drastically reduced 
from 50 pct after 1 hour to essentially nothing for aging temperature of $463 \mathrm{~K}\left(190^{\circ} \mathrm{C}\right)$.

\section{CONCLUSIONS}

The purpose of this study was to develop a repeatable baseline sample with a significant amount of residual stress and to develop aging relaxation curves for E319 aluminum alloy. From the results of this study, the following conclusions can be drawn for the E319 aluminum alloy:

1. Aging temperature was found to strongly affect the rate and total amount of measured relaxation in E319 aluminum alloy.

2. In order to achieve a 50 pct reduction in measured residual stress in E319 alloy, it is recommended that an aging temperature of $533 \mathrm{~K}\left(260^{\circ} \mathrm{C}\right)$ be used for 1 hour.

3. Negligible relaxation is achieved for aging temperature of $463 \mathrm{~K}\left(190^{\circ} \mathrm{C}\right)$ for all aging times tested in this study.

4. Samples quenched in boiling water have much lower residual stresses than those quenched into $20^{\circ} \mathrm{C}$ water.

5. All experiments were tested using aluminum with $31 \mu \mathrm{m}$ SDAS. If a finer/coarser microstructure is used, then the results may vary slightly from the reported values as the properties may become structure dependent.

6. Calibrating the model from the experimental data were essential to provide greater confidence when analyzing complex casting geometries.

\section{ACKNOWLEDGMENTS}

The authors would like to thank J.W. Zindel, James Boileau, and John Lasecki (Ford - Research and Innovation Center) for their assistance with the experimental and technical discussions.

\section{REFERENCES}

1. D.D. Hall and I. Mudawar: Int. J. Heat Mass Transf., 1996, vol. 39, pp. 81-95.

2. M. Tiryakioglu: Paper No. MF99-219, SME, Dearborn, MI, 1999.

3. M.L. Newman, B.J. Robinson, H. Sehitoglu, and J.A. Danzig: Metall. Mater. Trans. A, 2003, vol. 34A, pp. 1483-91.
4. J.S. Robinson and D.A. Tanner: Mater. Sci. Forum, 2002, vols. 40-407, pp. 355-60.

5. G.A. Webster: Mater. Sci. Forum, 2000, vols. 347-349, pp. 1-9.

6. A. Wedgewood: Mater. World, 2000, vol. 3, pp. 5-7.

7. R.C. Dorward: J. Mater. Proc. Technol., 1997, vol. 66, pp. 2529.

8. J.S. Robinson and D.A. Tanner: J. Eng. Mater. Technol., 2008, vol. 130, p. 031003.

9. D.A. Tanner and J.S. Robinson: Mater. Des., 2008, vol. 29, pp. 1489-96.

10. G.P. Donlan and J.S. Robinson: J. Mater. Process. Technol., 2004, vol. 153 , pp. $346-51$.

11. J.S. Robinson, S. Hossain, C.E. Truman, A.M. Paradowska, D.J. Hughes, R.C. Wimpy, and M.E. Fox: Mater. Sci. Eng., 2010, vol. A527, pp. 2603-12.

12. F. Carreno and O. Ruano: Mater. Sci. Eng., 1996, vol. A214, pp. $177-80$.

13. S. Denis, P. Archambault, E. Gautier, A. Simon, and G. Beck: Mater. Sci. Forum, 2000, vols. 347-349, pp. 184-89.

14. D. Walker: Advanced Materials \& Processes, 2001 Aug., vol. 159(8), pp. 30-33.

15. Y.C. Lam and K.S. Lian: Theor. Appl. Fract. Mech., 1989, vol. 12, pp. 59-66.

16. M. Kovac: J. Mater. Process. Technol., 1995, vol. 52, pp. 503-14.

17. G. Roy, M. Braid, and G. Shen: Comput. Struct., 2003, vol. 81, pp. 929-35.

18. M. Deqennoy, M. Ouaftouh, and M. Ourak: Ultrasonics, 1999, vol. 37 , pp. $365-72$

19. M. Landa and J. Plesek: Ultrasonics, 2002, vol. 40, pp. 531-35.

20. S.R. Yazdi, D. Retraint, and J. Lu: J. Strain Anal., 1998, vol. 33, pp. 449-58.

21. R.A. Owen, R.V. Preston, P.J. Withers, H.R. Shercliff, and P.J. Webster: Mater. Sci. Eng., 2003, vol. A346, pp. 159-67.

22. A. Lodini: Radiat. Phys. Chem., 2001, vol. 61, pp. 227-33.

23. P. Auburtin and N. Mortin: Mec. Ind., 2003, vol. 4, pp. 31925.

24. V. Lacarac, D.J. Smith, and M.J. Pavier: AIAA J., 2004, vol. 42 (7), pp. $1444-48$

25. M. Last, G. Luta, A. Orso, and S. Young: Comput. Stat. Data Anal., 2008, vol. 52, pp. 5215-28.

26. C.A. Cloutier, and J.W. Jones: Society Automotive Engineers Paper, 2000-01-0759.

27. S.C. Weakley-Bollin, W. Donlon, C. Wolverton, J.W. Jones, and J.E. Allison: Metall. Mater. Trans A, 2003, vol. 34A, p. 5137.

28. R. Jahn, W. Donlon, and J.E. Allison: Automotive Alloys III (PDF Only Version), 1999, TMS, Warrendale, PA, pp. 247-64. Available via $\mathrm{http}: / /$ doc.tms.org/Site/Products.nsf.

29. J. Boileau, C. Cloutier, L.A. Godlewski, P.A. Reeber-Symanski, C. Wolverton, and J.E. Allison: Paper No. 03M-168, SAE, Warrendale, PA, 2003.

30. H. Sehitoglu, X. Qing, T. Smith, H.J. Maier, and J. Allison: Metall. Mater. Trans. A, 2000, vol. 31A, pp. 139-51.

31. C.C. Engler-Pinto, Jr., H. Sehitoglu, and H.J. Maier: Thermomechanical Fatigue Behavior of Materials, 4th ed., ASTM International, West Conshohocken, PA, 2003.

32. K. Ishikawa, M. Maehara, and Y. Kobayashi: Mater. Sci. Eng. A, 2002, vol. A322, pp. 153-58.

33. S. Spigarelli, E. Evangelista, and S. Cucchieri: Mater. Sci. Eng. A, 2004, vols. A387-389, pp. 702-05. 